\title{
Strategies for the prevention of perinatal hepatitis $B$ transmission in a marginalized population on the Thailand-Myanmar border: a cost-effectiveness analysis
}

Angela Devine ${ }^{1,2^{*}}$ (D), Rebecca Harvey ${ }^{1}$, Aung Myat Min³, Mary Ellen T. Gilder ${ }^{3}$, Moo Koh Paw ${ }^{3}$, Joy Kang ${ }^{3}$, Isabella Watts ${ }^{3}$, Borimas Hanboonkunupakarn ${ }^{2,4}$, François Nosten ${ }^{1,3}$ and Rose McGready ${ }^{1,3}$

\begin{abstract}
Background: Data on the cost effectiveness of hepatitis B virus (HBV) screening and vaccination strategies for prevention of vertical transmission of HBV in resource limited settings is sparse.

Methods: A decision tree model of HBV prevention strategies utilised data from a cohort of 7071 pregnant women on the Thailand-Myanmar border using a provider perspective. All options included universal HBV vaccination for newborns in three strategies: (1) universal vaccination alone; (2) universal vaccination with screening of women during antenatal visits with rapid diagnostic test (RDT) plus HBV immune globulin (HBIG) administration to newborns of HBV surface antigen positive women; and (3) universal vaccination with screening of women during antenatal visits plus HBIG administration to newborns of women testing HBV e antigen positive by confirmatory test. At the time of the study, the HBIG after confirmatory test strategy was used. The costs in United States Dollars (US\$), infections averted and incremental cost effectiveness ratios (ICERs) were calculated and sensitivity analyses were conducted. A willingness to pay threshold of US\$1200 was used.

Results: The universal HBV vaccination was the least costly option at US\$4.33 per woman attending the clinic. The HBIG after (RDT) strategy had an ICER of US\$716.78 per infection averted. The HBIG after confirmatory test strategy was not cost-effective due to extended dominance. The one-way sensitivity analysis showed that while the transmission parameters and cost of HBIG had the biggest impact on outcomes, the HBIG after confirmatory test only became a cost-effective option when a low test cost was used or a high HBIG cost was used. The probabilistic sensitivity analysis showed that HBIG after RDT had an $87 \%$ likelihood of being cost-effective as compared to vaccination only at a willingness to pay threshold of US\$1200.

Conclusions: $\mathrm{HBIG}$ following confirmatory test is not a cost-effective strategy for preventing vertical transmission of HBV in the Thailand-Myanmar border population. By switching to HBIG following rapid diagnostic test, perinatal infections will be reduced by nearly one third. This strategy may be applicable to similar settings for marginalized populations where the confirmatory test is not logistically possible.
\end{abstract}

Keywords: Hepatitis B, Vaccination, Immunoglobulin, Resource limited settings, Migrants, Refugees

\footnotetext{
* Correspondence: angela@tropmedres.ac

${ }^{1}$ Centre for Tropical Medicine and Global Health, Nuffield Department of

Clinical Medicine, University of Oxford, Oxford, UK

${ }^{2}$ Mahidol-Oxford Tropical Medicine Research Unit, Mahidol University,

Bangkok, Thailand

Full list of author information is available at the end of the article
} 


\section{Background}

An estimated 240 million individuals are chronically infected with hepatitis B virus (HBV) worldwide $[1,2]$. An estimated 686,000 people die globally due to complications of hepatitis $\mathrm{B}$, including liver cirrhosis and hepatocellular carcinoma, which cause approximately $90 \%$ of deaths [3]. Transmission occurs through unprotected sex and body fluids [4], including the birth process, which leads to the majority of perinatal infections. Individuals who are $\mathrm{HBV}$ e-antigen positive $(\mathrm{HBeAg}+)$ are at the highest risk of transmitting to others. Of those who acquire the infection perinatally, $65 \%$ become chronic carriers of the disease and therefore are at a higher risk of morbidity and mortality as compared to $28 \%$ in those born to $\mathrm{HBeAg}$ - mothers [5]. An estimated 5-15\% of perinatal infections occur in-utero, which vaccination at birth does not prevent [6]; however, an estimated $90 \%$ of perinatal infections could be averted through infant $\mathrm{HBV}$ vaccination alongside administration of $\mathrm{HBV}$ immunoglobulin (HBIG) to the infant [7-12]. Due to problems of production, storage (cold chain) and cost, most low resource settings do not have access to HBIG. The reduction of mother to child transmission is a core intervention in the World Health Organisation (WHO) global health sector strategy on viral hepatitis, which proposes expansion of coverage from current its level of $38 \%$ to $90 \%$ by 2030 [13].

The HBV vaccine is the only routine childhood vaccine where prompt administration after birth (within $24 \mathrm{~h}$ ) is required to prevent transmission [14-16]. A modelling study [17] found that providing the first dose of HBV vaccine at birth could prevent an additional $16 \%$ of deaths from the disease, and a more recent study estimated that 210 million chronic infections had been prevented by 2015 through the vaccination of infants and neonates [18]. Universal $\mathrm{HBV}$ vaccination with a three to four dose schedule has a protective efficacy of 70-85\% [19], which increases up to $95 \%$ when administered with HBIG [20]. HBV vaccination has been shown to be cost effective [21-24], and nearly all countries have adopted the WHO recommendation of universal HBV vaccination without screening. In high resource settings, universal vaccination alongside antenatal maternal screening with HBIG administered in hospital to newborns of those who screen $\mathrm{HBV}$ surface antigen positive (HBsAg+) is considered to be a cost-effective strategy [7, 25, 26]. These screening strategies are often not taken up by low income countries due to the high costs [1]; yet it is often these low income countries that carry higher burdens of the disease. A lack of information exists on the cost-effectiveness of this strategy in resource limited settings, where late antenatal care is more common and the proportion of births at home is higher.
The Asia-Pacific region disproportionately shares the burden of $\mathrm{HBV}$, with $75 \%$ of chronic $\mathrm{HBV}$ carriers in the world found in Asia [27]. Vaccine programmes in Lao PDR, Vietnam and Cambodia have successfully lowered the prevalence of chronic HBV carriage to less than $2 \%$ by 2012 [28]. Myanmar, however, has continued to have areas of high HBV prevalence, especially in rural and border regions of Myanmar where a prevalence of $8.3 \%$ was recently reported [29]. This is widely attributed to the high percentage $\mathrm{HBeAg}+$ women of reproductive age in this region.

The aim of this study was to evaluate the costeffectiveness of options for the prevention of the perinatal HBV transmission in a marginalized (refugee and migrant) population on the Thailand-Myanmar border.

\section{Methods \\ Study site}

The Shoklo Malaria Research Unit (SMRU) was established in 1986 in response to the burden of cases and deaths in refugee camps due to malaria and other tropical diseases. Research is conducted alongside humanitarian healthcare work for marginalized populations including Myanmar migrants and refugees on the north western border of Thailand. Thailand and Myanmar are separated by the Moei River, which can be difficult for migrants to cross when trying to access care [30]. On the Myanmar side of the border healthcare is uncoordinated and, in some areas, non-existent or the expected fee for service is insurmountable. While Thailand's public health systems are strong, options for care for Myanmar women on the Thai side of the border are limited due to socio-economic, language, security and access barriers [31]. HBIG is not provided to non-Thai mothers unless payment can be guaranteed.

SMRU is comprised of three main clinics, one in Mae La refugee camp, and two at migrant sites, Mawker Thai and Wang Pha. Refugee camps were established in the area in 1986 as ethnic Karen from Myanmar fled armed conflict. Mae La refugee camp grew significantly in 1995-6 after additional conflict led to the merger of Shoklo, Bono Klo, Mae La and several other smaller camps. The population at the time of this analysis included an estimated 45,000 refugees [32]. Approximately $5-10 \%$ of those who attend the clinic at Mae La refugee camp are migrants or Karen minorities from surrounding villages [31]. The migrant sites, Wang Pha and Mawker Thai established birthing facilities in 2007 and 2010 and provide free services predominantly to agricultural migrants from Myanmar in rural areas $30 \mathrm{~km}$ north and $60 \mathrm{~km}$ south of Mae Sot, Tak Province, Thailand. Births in SMRU units are described in more detail in White et al. 2016 [33]. 
Birth in the area has traditionally been at home, which precludes timely HBV vaccination. Significant encouragement by clinic staff and free service provision has reduced home birth to $10-15 \%$ [34]. Women who deliver at the clinic are cared for by locally trained skilled birth attendants who can administer vaccinations and will refer women for caesarean sections at Thailand public hospitals if required [32, 34]. Care at the clinic is free and basic public health programmes including routine vaccinations are supported in part by external agencies, including the Thailand Department of Public Health. Treatment for liver cirrhosis, hepatocellular carcinoma and other conditions caused by HBV are unaffordable; and these conditions often result in premature death.

\section{Strategies for the prevention of HBV transmission}

Three strategies were evaluated with all options including universal $\mathrm{HBV}$ vaccination of infants:

1. Vaccine only: $\mathrm{HBV}$ vaccination provided to all newborns. No maternal screening is involved.

2. HBIG after RDT: Screening at the first antenatal visit using a point of care rapid diagnostic test (RDT) (One Step Bioline Hepatitis B Surface Antigen Test Strip, Pacific Biotech). Newborns of mothers who test $\mathrm{HBsAg}+$ during antenatal care or at delivery are given HBIG.

3. HBIG after confirmatory test: As for HBIG after RDT (above) with the additional step of confirmation testing in HBsAg + mothers for HBeAg status. Samples are sent to a local hospital to determine $\mathrm{HBeAg}$ status with a confirmatory test ( $\mathrm{HBeAg}$ electrochemiluminescence immunoassay, Roche Diagnostics, USA). Only the newborns of mothers who tests $\mathrm{HBeAg}$ + during an antenatal visit are given HBIG and this process requires first antenatal visit at least seven days before delivery to ensure that results are processed in time.

Table 1 summarizes the strategies. The HBIG after confirmatory test strategy was the current practice at SMRU at the time of the study; however, the vaccine only strategy was used as the base case option since most resource poor settings can provide this option if the cold-chain can be established. While some women do not attend for antenatal care, they first attend the clinic for delivery, which allows their newborns to be vaccinated within $12 \mathrm{~h}$ of birth. The newborns of women who deliver at home and present to the clinics within $24 \mathrm{~h}$ can also receive HBV vaccine and HBIG if appropriate. In accordance with the immunization policy for Thailand, it was assumed that all newborns who received the vaccine at birth also received the second and third dose of the vaccine.

A decision tree model was built in $\mathrm{R}$ statistical software [35] for a hypothetical cohort of 5000 women using a health care provider perspective. The model structure was based on a similar study in Taiwan by Chen et al. [7] and adapted to the SMRU setting (see Additional File 1). The effectiveness measure was perinatal infection of $\mathrm{HBV}$, caused through vertical transmission of the disease. The time horizon is from first contact with the SMRU clinic until childbirth. The long-term costs and effects of HBV were not included.

\section{Model parameters}

Table 2 shows all parameters used in the model. Parameters for all variables related to the population and clinic were taken from an anonymised mother and baby prospective cohort of 7071 registered mothers from the Thailand-Myanmar border area who either attended antenatal care at SMRU clinics or presented at the clinics to give birth [36]. The data analysis was conducted in STATA [37]. The prevalence of HBsAg in women seeking antenatal and delivery care at the clinic was determined onsite by RDT, and the confirmatory test was used to determine $\mathrm{HBeAg}$ status in those who tested HBsAg+. The data was collected using a standardised maternal and child health record used by trained skilled birth attendants and included all mothers registered at and SMRU clinic due to give birth between 1st January 2013 and 31st December 2014. Women who missed antenatal care and attended only for birth, or attended antenatal care but delivered at

Table 1 Details of the interventions included in each strategy for the prevention of perinatal hepatitis B transmission

\begin{tabular}{|c|c|c|c|}
\hline & Vaccine only & HBIG after RDT & HBIG after confirmatory test \\
\hline Vaccine for all newborns born in clinic & $x$ & $x$ & $x$ \\
\hline Screening for HBsAg with rapid diagnostic test during antenatal visit & & $x$ & $\mathrm{x}$ \\
\hline $\mathrm{HBIG}$ for newborns born to all mothers who test $\mathrm{HBsAg}+$ & & $x$ & \\
\hline Those who test $\mathrm{HBsAg}+$ during antenatal visit are screened for $\mathrm{HBeAg}$ & & & $x$ \\
\hline HBIG for newborns of mothers who attended antenatal clinic and tested HBeAg+ & & & $x$ \\
\hline
\end{tabular}


Table 2 Parameter values including range used in sensitivity analysis

\begin{tabular}{|c|c|c|c|c|c|}
\hline Parameter & Base value & Low value & High value & $\begin{array}{l}\text { Distribution } \\
\left(\text { Parameters }^{\mathrm{a}}\right)\end{array}$ & Source \\
\hline Probability HBsAg + for all women attending SMRU clinics & 0.07 & 0.07 & 0.08 & Beta $(490.6,6187.1)$ & SMRU data with $95 \% \mathrm{Cl}$ \\
\hline Probability HBeAg carrier if $\mathrm{HBsAg}+$ & 0.34 & 0.29 & 0.39 & Beta $(130.1,253.6)$ & SMRU data with $95 \% \mathrm{Cl}$ \\
\hline $\begin{array}{l}\text { Probability women receive antenatal care (attend clinic } \\
\text { at least } 7 \text { days before delivery) }\end{array}$ & 0.96 & 0.96 & 0.96 & Beta $(999.9,41.4)$ & SMRU data with $95 \% \mathrm{Cl}$ \\
\hline Probability of clinic delivery after attending antenatal care & 0.90 & 0.90 & 0.91 & Beta $(999.9,107.6)$ & SMRU data with $95 \% \mathrm{Cl}$ \\
\hline $\begin{array}{l}\text { Probability that newborns birthed at home after attending } \\
\text { antenatal care will receive HBV vaccine at the clinic } \\
\text { (present within } 12 \mathrm{~h} \text { ) }\end{array}$ & 0.15 & 0.12 & 0.17 & Beta $(94.3,552.5)$ & SMRU data with $95 \% \mathrm{Cl}$ \\
\hline $\begin{array}{l}\text { Probability of HBV perinatal infection for HBeAg- mothers } \\
\text { without vaccination }\end{array}$ & 0.11 & 0.05 & 0.31 & Beta $(1.7,13.5)$ & $\begin{array}{l}{[38,39,41,42] \text { with low from }} \\
{[42] \text { and high from [38] }}\end{array}$ \\
\hline $\begin{array}{l}\text { Probability of HBV perinatal infection for } \mathrm{HBeAg}+\text { mothers } \\
\text { without vaccination }\end{array}$ & 0.84 & 0.66 & 1.00 & Beta $(15.5,2.95)$ & $\begin{array}{l}{[38,40-42] \text { with low from [41] }} \\
\text { and high from [39] }\end{array}$ \\
\hline $\begin{array}{l}\text { Probability of HBV perinatal infection for HBeAg- mothers } \\
\text { if given vaccine }\end{array}$ & 0.07 & 0.00 & 0.13 & Beta $(4.1,57.9)$ & [7] \\
\hline $\begin{array}{l}\text { Probability of HBV perinatal infection for } \mathrm{HBeAg}+\text { mothers } \\
\text { if given vaccine }\end{array}$ & 0.34 & 0.21 & 0.43 & Beta $(24.3,47.6)$ & [7] \\
\hline $\begin{array}{l}\text { Probability of HBV perinatal infection for HBsAg- mothers } \\
\text { if given vaccine and HBIG }\end{array}$ & 0.01 & 0.00 & 0.03 & Beta $(1.6,159.0)$ & [7] \\
\hline $\begin{array}{l}\text { Probability of HBV perinatal infection for } \mathrm{HBeAg}+\text { mothers } \\
\text { if given vaccine and } \mathrm{HBIG}\end{array}$ & 0.13 & 0.06 & 0.29 & Beta $(3.1,21.7)$ & [7] \\
\hline Sensitivity of the RDT for HBsAg & 0.98 & 0.90 & 1.00 & Beta $(24.3,0.5)$ & [44] with assumed range \\
\hline Specificity of the RDT for HBsAg & 0.97 & 0.95 & 0.98 & Beta $(306.4,9.9)$ & [29] with 95\% Cl \\
\hline Sensitivity of the confirmatory test for $\mathrm{HBeAg}$ & 1.00 & 0.90 & 1.00 & Beta $(40.0,0.0)$ & [43] with assumed range \\
\hline Specificity of the confirmatory test for $\mathrm{HBeAg}$ & 1.00 & 0.90 & 1.00 & Beta $(40.0,0.0)$ & [43] with assumed range \\
\hline \multicolumn{6}{|l|}{ Costs } \\
\hline Cost of HBV vaccinations & 4.71 & 2.36 & 7.07 & Gamma $(16.1,0.3)$ & $\begin{array}{l}\text { SMRU records } \pm 50 \% \text {. Cost of } \\
\text { single vaccination at birth plus } \\
\text { two doses of HBV diphtheria } \\
\text { tetanus and pertussis combined } \\
\text { vaccine given at } 2 \text { and } 6 \text { months }\end{array}$ \\
\hline Cost of a RDT for HBsAg & 1.17 & 0.59 & 1.76 & Gamma $(16.1,0.1)$ & SMRU records $\pm 50 \%$ \\
\hline Cost of a confirmatory test for HBeAg at local hospital & 17.85 & 8.93 & 26.78 & Gamma $(16.1,1.1)$ & SMRU records $\pm 50 \%$ \\
\hline Cost per dose of HBIG & 43.00 & 21.50 & 64.50 & Gamma $(16.1,2.7)$ & SMRU records $\pm 50 \%$ \\
\hline
\end{tabular}

All costs are in 2015 United States Dollars. Confidence interval (Cl)

aParameters: Beta (alpha, beta), Gamma (shape, scale)

home and presented at the clinic on the same day were presumed eligible for HBIG. The probability of presenting at the clinic within $12 \mathrm{~h}$ was calculated from those who attended antenatal care but delivered at home and presented their newborn at the clinic for cord care and birth weight measurement, as date of birth and date of weight is recorded routinely.

Transmission rates when using vaccine or vaccine with HBIG were taken from a previous economic evaluation [7]. Transmission rates without vaccine were taken from a literature review of studies in Asia [38-42]. The diagnostic accuracy of the confirmatory test was taken from the literature [43] as was the sensitivity of the RDT [44]. The specificity of the RDT was taken from a local study that showed that it was lower than previously reported [29].
Unit costs were taken from the 2015 financial records of the clinics and include those for diagnostic tests, vaccination and HBIG at the clinic. As all women are encouraged to deliver at the clinics, the cost of delivery was not included. All costs are reported in 2015 United States Dollars (USD). Unit costs that were reported as Thai Baht were converted into USD using the average exchange rate for 2015 (1 Thai baht $=0.029$ USD) [45]

\section{Analysis}

The total costs and perinatal infections were calculated for each strategy, and the results were plotted on a costeffectiveness plane. The strategies were then ordered from the least to the most expensive. Any options that were dominated due to averting fewer perinatal infections than the previous less expensive strategy were then 
removed. The incremental cost effectiveness ratio (ICER) for the non-dominated strategies was calculated using the following formula:

$$
\frac{C_{B}-C_{A}}{-\left(E_{B}-E_{A}\right)}
$$

Any options with extended dominance were then removed from the analysis. A willingness to pay threshold of US $\$ 1200$ was used, which is one gross domestic product (GDP) per capita for Myanmar [46]. A one way sensitivity analysis was conducted to test the impact of each parameter on the ICER and whether each strategy was cost effective. ICER changes greater than $1 \%$ of the base case ICER were reported. A probabilistic sensitivity analyses (PSA) was conducted to incorporate the uncertainty of parameter estimates over 10,000 sampling iterations. The sum of squared differences was minimized from the specified ranges to produce the shape values for the beta and gamma distributions and random numbers were generated from these distributions. The PSA produced a mean estimate and 95\% credible intervals (CrIs) for the results. The low and high values and distributions used for the sensitivity analyses are shown in Table 2. Since this setting is resource-constrained, a one GDP per capita threshold could still be too high [47, 48], though it is plausible that averting an infection would avert more than one disability-adjusted life-year. Accordingly, the cost-effectiveness acceptability curve produced by the PSA examined the likelihood of interventions being cost-effective at different willingness to pay thresholds.

\section{Results}

Table 3 presents the results for the base case analysis. The cohort costs ranged from US\$21,673.15 for the vaccine only strategy to US\$47,477.10 for the HBIG after $R D T$ strategy; these are equivalent to US\$4.33 to US\$9.50 per woman presenting at the clinic. The vaccine only had the lowest effectiveness with 64 perinatal infections in the hypothetical cohort of 5000 newborns. The number of infections was reduced to 41 with the $H B I G$ after confirmatory test and 28 with the HBIG after RDT strategy. The HBIG after confirmatory test strategy were removed due to extended dominance by the HBIG after $R D T$ strategy, which had an ICER of US\$716.78 per infection averted, which was below the willingness to pay threshold of US $\$ 1200$. The PSA produced a 95\% CrI of US\$343.00-2159.90 for the ICER. Figure 1 shows the cost-effectiveness plane.

Figure 2 shows the results of the one way sensitivity analysis on the ICER for HBIG after RDT strategy as compared to the vaccine only strategy. The three parameters that had the largest impact on the ICER of the $H B I G$ after RDT strategy were all related to transmission: the probability of HBV perinatal infection for both $\mathrm{HBeAg}+$ and HBeAg- mothers when newborns were given vaccine and the probability of HBV perinatal infection for $\mathrm{HBeAg}+$ mothers if newborns were given vaccine and HBIG. A 50\% change in the cost of HBIG also caused the ICER to change by nearly $40 \%$ in both directions with a low cost causing a reduction in the ICER. When the high value for the probability of HBV perinatal infection for $\mathrm{HBeAg}+$ mothers when newborns were given the vaccine and HBIG was raised to $43 \%$, the HBIG after RDT strategy had an ICER of US\$1462, which was the only time the strategy rose above the threshold of US $\$ 1200$. For all other parameter values evaluated in the one-way sensitivity analysis, the HBIG after RDT strategy remained below US $\$ 1200$.

The HBIG after confirmatory test was only nondominated for two parameter values. The first was when a low cost for the confirmatory test (US\$8.93) was used, which resulted in an ICER of US\$636.14 for the HBIG after confirmatory test and an ICER of US\$846.16 for the HBIG after RDT strategy. The second parameter value was the high HBIG cost (US\$64.50) was used. This resulted in ICERs of US\$925.90 and US\$1097.90 for the HBIG after confirmatory test and the HBIG after RDT strategy, respectively. Figure 3 shows the cost-effectiveness acceptability curve for the comparison between HBIG after $R D T$ and vaccine only. At a willingness to pay threshold of US\$1200 per perinatal infection averted, the HBIG after RDT strategy had an $87 \%$ likelihood of being costeffective. If the willingness to pay threshold was lowered to US $\$ 600$ per infection averted, the likelihood of the HBIG after RDT strategy being cost-effective dropped to $32 \%$.

\section{Discussion}

Our results indicate that two cost-effective strategies are available for the prevention of perinatal transmission of

Table 3 Cost-effectiveness results for cohort of 5000 women (costs are in USD)

\begin{tabular}{llllll}
\hline Strategy & Total costs & Incremental costs & Total infections & Infections averted & ICER $^{\text {a }}$ \\
\hline Vaccine only & $\$ 21,673.15$ & base case & 64 & base case & base case \\
HBIG after confirmatory test & $\$ 40,553.86$ & - & 41 & - & extended dominance \\
HBIG after RDT & $\$ 47,477.10$ & $\$ 25,803.95$ & 28 & 36 & $\$ 716.78$ \\
\hline
\end{tabular}

${ }^{\mathrm{a}} \mathrm{ICER}=$ Incremental cost-effectiveness ratio 


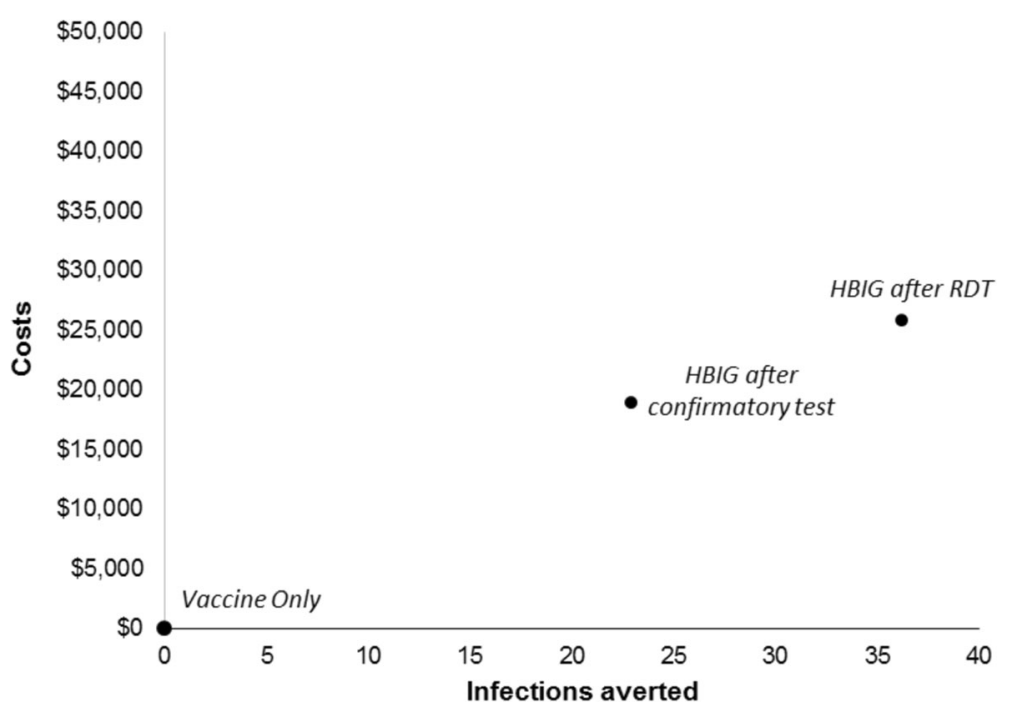

Fig. 1 Cost-effectiveness plane with vaccine only as the base case comparator for infections averted

HBV in a population on the Thailand-Myanmar border. With an ICER of US\$716.78, the HBIG after RDT strategy is cost-effective at the one GDP per capita threshold of US\$1200 per hepatitis B infection averted, which would result in even greater benefits in terms of disability-adjusted life years averted. In such a resourceconstrained setting where a dose of HBIG can be equivalent to one month's salary for the average family, this intervention may still not be feasible. Assuming that funding is available, a switch from the current practice of HBIG after confirmatory test to the HBIG after RDT strategy, infections could be reduced by nearly a third for a relatively small increase in the overall programme costs. Importantly, the HBIG after RDT strategy was consistently a cost-effective option in the one-way sensitivity analysis. Our results are similar to a study conducted in Taiwan, where maternal screening for HBsAg and HBIG given to all infants of HBV positive mothers along with universal vaccination was also found to be cost effective at all levels of endemicity [7].
Two cost parameters, the low value for the confirmatory test and the high value for the HBIG, had a significant impact on the results of the one-way sensitivity analysis, shifting the HBIG after confirmatory test to become a cost-effective strategy. As confirmatory tests require facilities found at a hospital, it is unlikely to drop in price by $50 \%$ to the low value of US\$8.93 that was used in this analysis. Ideally, a new rapid diagnostic test would have confirmatory capability and could make the HBIG after confirmatory test a more viable option, as HBIG costs are also very unlikely to come down in price.

Few economic evaluations of strategies involving HBV screening in low resource settings have been published; these studies mainly focus on universal vaccination, which is consistently cost-effective with the exception of very low endemicity settings [21, 24, 49-52]. In most high resource settings, a low prevalence of HBV has produced mixed cost-effectiveness results [53-55]. Many earlier studies have found that universal maternal screening programmes are not cost effective compared to screening

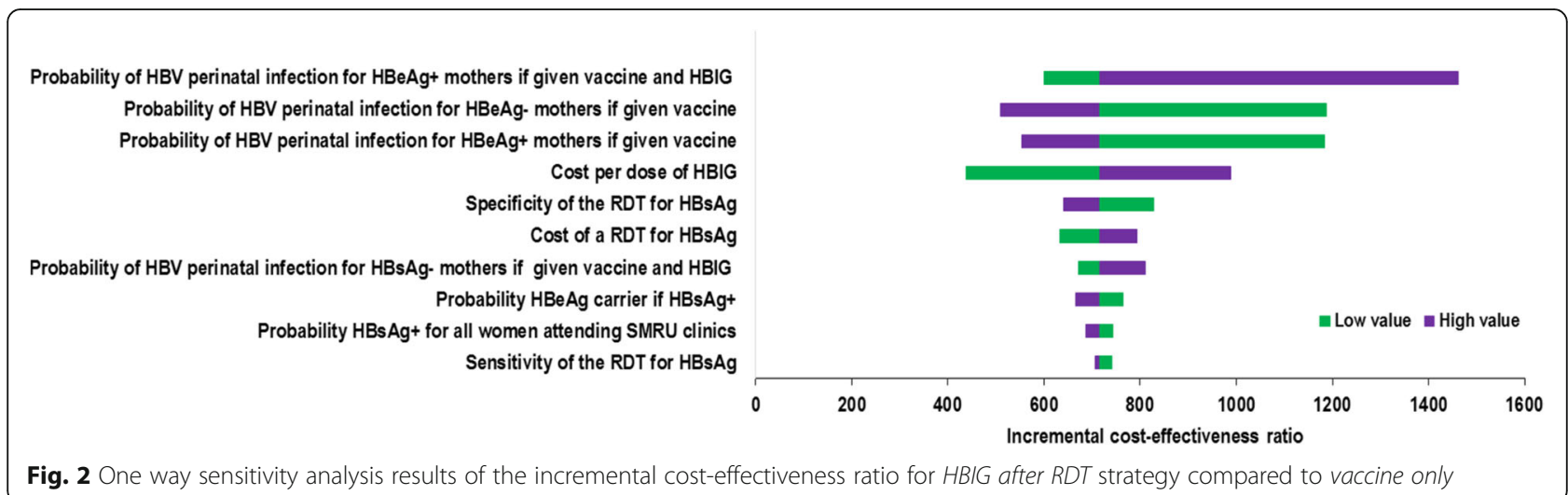

Fig. 2 One way sensitivity analysis results of the incremental cost-effectiveness ratio for HBIG after RDT strategy compared to vaccine only 


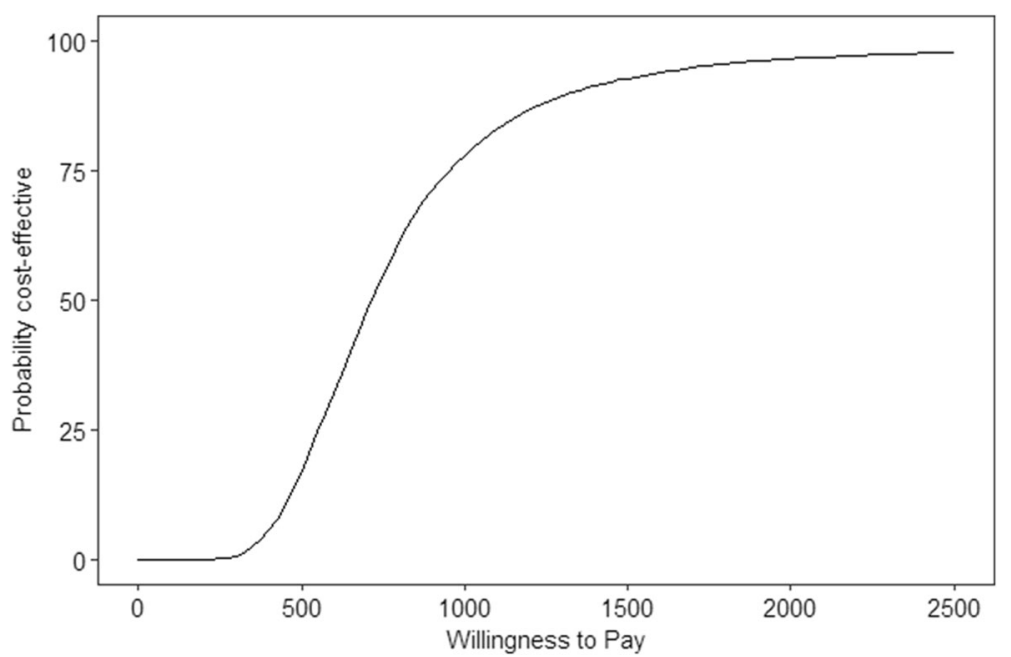

Fig. 3 Cost-effectiveness acceptability curve for HBIG after RDT as compared to vaccine only

only those who are at high risk; however, more recent studies have found universal antenatal screening for HBV to be cost effective [56, 57]. In almost all high resource settings, HBIG is offered to infants born to known HBsAg + mothers. The costs of HBIG are generally covered by long-sighted policies for HBV control. Recent publications suggest that offering HBIG only to those who are willing to pay for it would result in zero uptake in marginalized populations existing on subsistence daily wages due to the high cost [58].

There is evidence from previous settings of high endemicity that HBV transmission can be reduced and elimination of the disease could be possible [59]. The use of HBIG could accelerate this process and this study has shown it is a cost effective strategy to use in a low resource setting. As settings achieve lower endemicity, the cost-effectiveness of interventions to reduce mother to child transmission of HBV will decrease [7, 50], which may make it even less viable to continue with the $H B I G$ after $R D T$ strategy when this money could be directed towards other healthcare needs.

The RDT in use at the site carries a false positive rate of $3.1 \%$ (95\%CI 1.7-5.4) [29], which raises the possibility of a child receiving $\mathrm{HBIG}$ when they do not need it if the HBIG after RDT strategy were adopted. Common mild adverse effects of HBIG include pyrexia, malaise, drowsiness and urticaria with rare reports of serious adverse effects including anaphylaxis [60]. The HBIG after confirmatory test option eliminates this problem, but we were unable to find estimates in the literature for the rate of serious events of HBIG administration in neonates without HBV, making it difficult to directly include in the model. In addition, when the specificity of the RDT was reduced to $95 \%$, which is the low end of the $\mathrm{CI}$ recently reported by Banks et al. for this population [29], the ICER rose from US\$716.78 to US\$828.97, decreasing the cost-effectiveness of the HBIG after RDT strategy. Poor diagnostic accuracy has been reported in the literature so finding a locallydistributed test with better specificity may be advantageous [61]. RDT tests for HBV have significantly raised the safety of blood for transfusion in resource limited settings when used to exclude potentially positive cases from donating blood [61]. Pragmatically the same RDT used to screen blood donors was used to screen pregnant women at the point of care in this setting. While tests with better diagnostic accuracy are being developed, their feasibility in limited-resource settings must be considered [61]. A more specific RDT would increase the cost-effectiveness of the HBIG after RDT strategy, but the increased cost associated with such an RDT may offset this or cause it to be less cost-effective than reported here.

Our study has several limitations. Firstly, long-term effects including morbidity, mortality and costs and effects of HBV infection are not evaluated in our analysis. Also, not all of those who are infected with HBV will suffer long term damage from the disease. Of those infected at birth, 15-25\% will acquire cirrhosis of the liver or develop hepatic carcinoma $[4,62]$. In clinics such as SMRU, and most limited-resource settings where HBV and associated diseases cannot be treated due to resource constraints, the health gains associated with more thorough neonatal intervention are considerable [63].

Another limitation is the exclusion of data on multiple births, stillbirths, miscarriages and women who delivered at other clinics or hospitals. Approximately $1 \%$ of women in this population have multiple births. These could impact the model results; however, due to the robustness of the model in relation to transmission rate changes, it is unlikely to alter the cost effectiveness 
of any of the strategies. Other important data limitations relate to the uncertainties surrounding the parameters of the model. In particular, a great deal of uncertainty surrounds the transmission probabilities, especially for those who do not receive vaccination or HBIG. For transmission rates for $\mathrm{HBsAg}$ carriers and $\mathrm{HBeAg}$ carriers who did not receive a vaccine or vaccine with HBIG, the model was robust to variation in the sensitivity analysis. The transmission rates for HBsAg carriers and HBeAg carriers who were vaccinated with or without HBIG, however, had a sizeable impact on the ICER.

Finally, the HBV transmission rates after vaccination and after vaccination and HBIG were based on studies where participants had received all three vaccines as this is the recommendation of the Thai government. Yet in this population, as in most low resource settings, low rates of full vaccination coverage exist. While in Mae La refugee camp the full course coverage was as high as $98 \%$, it may be much lower in migrant settings where access or migration due to work result in reduced completion rates [64]. The effect of the vaccination and HBIG on vertical transmission of HBV will most likely be provided by the dose given at birth and therefore poor uptake of the second and third vaccine would have a low impact on the results of this study [17]. Newer treatment modalities, such as the use of tenofovir to reduce vertical transmission of HBV in resource limited settings, should be considered due to their improved efficacy and potential cost benefits [65]. Tenofovir would be ideal in middle to high HBV endemic settings with high rates of homebirth. The high price of vaccines [66] alongside country-wide HBIG shortages experienced in this setting in 2016 make exploring the option of Tenofovir even more attractive.

\section{Conclusions}

This study presents the first economic evaluation of strategies for the prevention of vertical transmission in a marginalized population of HBV on the ThailandMyanmar border population. The results demonstrate that the current clinical strategy of HBIG after confirmatory test was not cost effective when compared to HBIG after RDT. Barriers to implementing HBIG after $R D T$ strategy in limited-resource settings remain including: quality of the HBV RDT (risking administration of HBIG to infants without risk of HBV), HBIG supply problems, and home births. This study adds to the very limited body of literature on the cost effectiveness of HBV prevention strategies for vertical transmission in low resource settings. The use of HBIG after $R D T$ could be considered in low resource settings, particularly those with high HBV prevalence; however, the need for more cost-effective options for low resource settings is urgent.

\section{Additional file}

Additional file 1: Model structure. Decision tree diagrams for hepatitis $B$ prevetion in newborns: (A) Vaccine only (B) HBIG after RDT (C) HBIG after confirmatory test. (PDF $99 \mathrm{~kb}$ )

\section{Abbreviations}

HBeAg +: Hepatitis B e-antigen positive; HBIG: Hepatitis B immunoglobulin; HBsAg +: Hepatitis B surface antigen positive; HBV: Hepatitis B virus; ICER: Incremental cost-effectiveness ratio; RDT: Rapid diagnostic test; SMRU: Shoklo Malaria Research Unit; WHO: World Health Organisation

\section{Acknowledgments \\ The data generated for use in this analysis would not be possible without the support and cooperation of marginalized populations both in terms of women attending antenatal care and local SMRU staff who provide a $24 \mathrm{~h}$ health service in this rural setting and we would like to thank them. Specific thanks is also in order to the laboratory and data teams at the field sites and centrally in Mae Sot for making this study possible.}

\section{Funding}

This study was part of the Wellcome-Trust Major Overseas Programme in SE Asia (grant number 106698/Z/14/Z).

\section{Availability of data and materials}

The dataset analysed during the current study are available in the Oxford University Research Archive repository, https://doi.org/10.5287/

bodleian:6qQMrJBOX

\section{Authors' contributions}

$\mathrm{AD}, \mathrm{RH}$ and $\mathrm{RM}$ analysed the patient data, developed the model structure, interpreted the results and wrote the first draft of the paper. AMM, METG, MKP, JK and IW collected the data. $\mathrm{BH}$ provided valuable comments on the manuscript. AD performed the model analysis. All authors read and approved the final manuscript.

Ethics approval and consent to participate

Ethical approval for the study was confirmed by Oxford Tropical Research Ethics Committee (OxTREC reference: 28-09) and locally by the Tak Province Community Ethics Advisory Board (T-CAB reference: TCAB-2/1/2015).

Consent for publication

Not applicable.

\section{Competing interests}

The authors declare that they have no competing interests.

\section{Publisher's Note}

Springer Nature remains neutral with regard to jurisdictional claims in published maps and institutional affiliations.

\section{Author details}

${ }^{1}$ Centre for Tropical Medicine and Global Health, Nuffield Department of Clinical Medicine, University of Oxford, Oxford, UK. ${ }^{2}$ Mahidol-Oxford Tropical Medicine Research Unit, Mahidol University, Bangkok, Thailand. ${ }^{3}$ Shoklo Malaria Research Unit, Mahidol-Oxford Tropical Medicine Research Unit Mahidol University, Bangkok, Thailand. ${ }^{4}$ Department of Clinical Tropical Medicine, Faculty of Tropical Medicine, Mahidol University, Bangkok, Thailand.

Received: 27 January 2017 Accepted: 1 August 2017

Published online: 09 August 2017

\section{References}

1. World Health Organisation. Global policy report on the prevention and control of viral hepatitis. http://www.who.int/hepatitis/publications/global_ report/en/. Accessed 1 May 2016.

2. Schweitzer A, Horn J, Mikolajczyk RT, Krause G, Ott JJ. Estimations of worldwide prevalence of chronic hepatitis B virus infection: a systematic 
review of data published between 1965 and 2013. Lancet. 2015;386(10003): $1546-55$.

3. GBD 2013 Mortality and Causes of Death Collaborators. Global, regional, and national age-sex specific all-cause and cause-specific mortality for 240 causes of death, 1990-2013: a systematic analysis for the Global Burden of Disease Study 2013. Lancet. 2015;385(9963):117-71.

4. Bzowej NH. Hepatitis B therapy in pregnancy. Curr Hepat Rep. 2010;9(4):197-204.

5. Li Z, Hou X, Cao G. Is mother-to-infant transmission the most important factor for persistent HBV infection? Emerg Microbes Infect. 2015;4(5):e30

6. Ghendon Y. Perinatal transmission of hepatitis B virus in high-incidence countries. J Virol Methods. 1987;17(1-2):69-79.

7. Chen SC, Toy M, Yeh JM, Wang JD, Resch S. Cost-effectiveness of augmenting universal hepatitis B vaccination with immunoglobin treatment. Pediatrics. 2013;131(4):e1135-43.

8. Stevens CE, Taylor PE, Tong MJ, Toy PT, Vyas GN, Nair PV, Weissman JY, Krugman $S$. Yeast-recombinant hepatitis B vaccine. Efficacy with hepatitis B immune globulin in prevention of perinatal hepatitis B virus transmission. JAMA. 1987;257(19):2612-6.

9. Stevens CE, Toy PT, Tong MJ, Taylor PE, Vyas GN, Nair PV, Gudavalli M, Krugman S. Perinatal hepatitis B virus transmission in the United States. Prevention by passive-active immunization. JAMA. 1985;253(12):1740-5.

10. Zanetti AR, Magliano EM, Tanzi E, Ferroni P, Pirovano G, Pizzocolo G, Pillan $\mathrm{N}$, Zunin C. HBIG immunoprophylaxis of babies born to HBsAg carrier mothers. Dev Biol Stand. 1983;54:383-9.

11. Wiseman E, Fraser MA, Holden S, Glass A, Kidson BL, Heron LG, Maley MW, Ayres A, Locarnini SA, Levy MT. Perinatal transmission of hepatitis B virus: an Australian experience. Med J Aust. 2009;190(9):489-92.

12. Wheeley SM, Jackson PT, Boxall EH, Tarlow MJ, Gatrad AR, Anderson J, Bissenden J. Prevention of perinatal transmission of hepatitis B virus (HBV): a comparison of two prophylactic schedules. J Med Virol. 1991;35(3):212-5.

13. World Health Organization. Global Health Sector Strategy on Viral Hepatitis, 2016-2021. Geneva: World Health Organization; 2016.

14. Mast EE, Margolis HS, Fiore AE, Brink EW, Goldstein ST, Wang SA, Moyer LA, Bell BP, Alter MJ. A comprehensive immunization strategy to eliminate transmission of hepatitis B virus infection in the United States: recommendations of the Advisory Committee on Immunization Practices (ACIP) part 1: immunization of infants, children, and adolescents. MMWR Recomm Rep. 2005;54(Rr-16):1-31.

15. Marion SA, Tomm Pastore M, Pi DW, Mathias RG. Long-term follow-up of hepatitis B vaccine in infants of carrier mothers. Am J Epidemiol. 1994; 140(8):734-46

16. Resti M, Azzari C, Rossi ME, Adami Lami C, Tucci F, Vierucci A. Five-year follow-up of vaccination against hepatitis $B$ virus in newborns vaccinated with a reduced number of doses. Vaccine. 1991;9(1):15-8.

17. Goldstein ST, Zhou F, Hadler SC, Bell BP, Mast EE, Margolis HS. A mathematical model to estimate global hepatitis $B$ disease burden and vaccination impact. Int J Epidemiol. 2005;34(6):1329-39.

18. Nayagam S, Thursz M, Sicuri E, Conteh L, Wiktor S, Low-Beer D, Hallett TB. Requirements for global elimination of hepatitis B: a modelling study. Lancet Infect Dis. 2016;16(12):1399-408.

19. Wong VC, Ip HM, Reesink HW, Lelie PN, Reerink-Brongers EE, Yeung CY, Ma HK. Prevention of the HBsAg carrier state in newborn infants of mothers who are chronic carriers of $\mathrm{HBSAg}$ and $\mathrm{HBeAg}$ by administration of hepatitis-B vaccine and hepatitis-B immunoglobulin. Double-blind randomised placebo-controlled study. Lancet. 1984;1 (8383):921-6.

20. Beasley RP. Rocks along the road to the control of HBV and HCC. Ann Epidemiol. 2009;19(4):231-4.

21. Tu HA, Woerdenbag HJ, Kane S, Riewpaiboon A, van Hulst M, Postma MJ. Economic evaluations of hepatitis B vaccination for developing countries. Expert Rev Vaccines. 2009;8(7):907-20.

22. Tilson $L$, Thornton L, O'Flanagan D, Johnson H, Barry M. Cost effectiveness of hepatitis B vaccination strategies in Ireland: an economic evaluation. Eur J Pub Health. 2008;18(3):275-82.

23. Beutels P. Economic evaluations applied to HB vaccination: general observations. Vaccine. 1998;16(Suppl):S84-92.

24. Lee D, Park SM. Cost-effectiveness analysis of hepatitis B vaccination strategies to prevent perinatal transmission in North Korea: selective vaccination vs. universal vaccination. PLoS One. 2016;11(11):e0165879.

25. Barbosa C, Smith EA, Hoerger TJ, Fenlon N, Schillie SF, Bradley C, Murphy TV. Cost-effectiveness analysis of the national perinatal hepatitis B prevention program. Pediatrics. 2014;133(2):243-53.
26. Fan L, Owusu-Edusei K Jr, Schillie SF, Murphy TV. Cost-effectiveness of testing hepatitis B-positive pregnant women for hepatitis B e antigen or viral load. Obstet Gynecol. 2014;123(5):929-37.

27. Zhu RX, Seto WK, Lai CL, Yuen MF. Epidemiology of hepatocellular carcinoma in the Asia-Pacific region. Gut Liver. 2016;10(3):332-9.

28. Hennessey K, Mendoza-Aldana J, Bayutas B, Lorenzo-Mariano KM, Diorditsa S. Hepatitis B control in the World Health Organization's western Pacific region: targets, strategies, status. Vaccine. 2013;31(Suppl 9):J85-92.

29. Banks T, Kang J, Watts I, Tyrosvoutis ME, Min AM, Tun NW, Keereecharoen L, Simmawong W, Wanyatip S, Hanboonkunupakarn B, et al. High hepatitis B seroprevalence and risk factors for infection in pregnant women on the Thailand-Myanmar border. J Infect Dev Ctries. 2016;10(4):384-8.

30. Carrara VI, Lwin KM, Phyo AP, Ashley E, Wiladphaingern J, Sriprawat K, Rijken M, Boel M, McGready R, Proux S, et al. Malaria burden and artemisinin resistance in the mobile and migrant population on the Thai-Myanmar border, 1999-2011: an observational study. PLoS Med. 2013;10(3):e1001398.

31. McGready R, Boel M, Rijken MJ, Ashley EA, Cho T, Moo O, Paw MK, Pimanpanarak M, Hkirijareon L, Carrara VI, et al. Effect of early detection and treatment on malaria related maternal mortality on the north-western border of Thailand 1986-2010. PLoS One. 2012;7(7):e40244.

32. Parr M, Dabu CP, Wai NS, Say PS, Ner M, Tun NW, Min A, Gilder ME, Nosten FH, McGready R. Clinical audit to enhance safe practice of skilled birth attendants for the fetus with nuchal cord: evidence from a refugee and migrant cohort. BMC Pregnancy Childbirth. 2014;14:76.

33. White AL, Min TH, Gross MM, Kajeechiwa L, Thwin MM, Hanboonkunupakarn B, Than HH, Zin TW, Rijken MJ, Hoogenboom G, et al. Accelerated training of skilled birth attendants in a marginalized population on the Thai-Myanmar border: a multiple methods program evaluation. PLoS One. 2016;11(10):e0164363.

34. White AL, Carrara VI, Paw MK, Malika, Dahbu C, Gross MM, Stuetz W, Nosten $\mathrm{FH}$, Mcgready R. High initiation and long duration of breastfeeding despite absence of early skin-to-skin contact in Karen refugees on the ThaiMyanmar border: a mixed methods study. Int Breastfeed J. 2012;7(1):19.

35. R Core Team. R. A language and environment for statistical computing. Vienna: R Foundation for Statistical Computing; 2017.

36. Devine A, Waithira N. Hepatitis B in cohort of pregnant women on Thailand-Myanmar border. 2017. https://doi.org/10.5287/bodleian: 6qQMrJBOX

37. StataCorp. Stata Statistical Software: Release 14. College Station: StataCorp LP; 2015.

38. Beasley RP, Trepo C, Stevens CE, Szmuness W. The e antigen and vertical transmission of hepatitis B surface antigen. Am J Epidemiol. 1977;105(2):94-8.

39. Okada K, Kamiyama I, Inomata M, Imai M, Miyakawa Y. E antigen and anti-e in the serum of asymptomatic carrier mothers as indicators of positive and negative transmission of hepatitis B virus to their infants. N Engl J Med. 1976;294(14):746-9.

40. Beasley RP, Hwang LY, Lee GC, Lan CC, Roan CH, Huang FY, Chen CL. Prevention of perinatally transmitted hepatitis $B$ virus infections with hepatitis B immune globulin and hepatitis B vaccine. Lancet. 1983;2(8359):1099-102.

41. Xu ZY, Liu CB, Francis DP, Purcell RH, Gun ZL, Duan SC, Chen RJ, Margolis $H S$, Huang $C H$, Maynard JE. Prevention of perinatal acquisition of hepatitis B virus carriage using vaccine: preliminary report of a randomized, doubleblind placebo-controlled and comparative trial. Pediatrics. 1985;76(5):713-8.

42. Nayak NC, Panda SK, Zuckerman AJ, Bhan MK, Guha DK. Dynamics and impact of perinatal transmission of hepatitis B virus in North India. J Med Virol. 1987;21(2):137-45.

43. Ratnam S, Tobin AM. Comparative evaluation of commercial enzyme immunoassay kits for detection of hepatitis B seromarkers. J Clin Microbiol. 1987;25(2):432-3.

44. Scheiblauer H, El-Nageh M, Diaz S, Nick S, Zeichhardt H, Grunert HP, Prince A. Performance evaluation of 70 hepatitis B virus (HBV) surface antigen ( $\mathrm{HBs} A g$ ) assays from around the world by a geographically diverse panel with an array of HBV genotypes and HBsAg subtypes. Vox Sang. 2010;98(3 Pt 2):403-14.

45. OANDA. Currency Converter-Historical Exchance Rates https://www.oanda. com/fx-for-business/historical-rates. Accessed 13 July 2016.

46. The World Bank. GDP per capita (current US\$) for Myanmar http://data. worldbank.org/indicator/NY.GDP.PCAP.CD?locations=MM. Accessed 19 Aug 2016.

47. Marseille E, Larson B, Kazi DS, Kahn JG, Rosen S. Thresholds for the costeffectiveness of interventions: alternative approaches. Bull World Health Organ. 2015;93(2):118-24. 
48. Bertram MY, Lauer JA, De Joncheere K, Edejer T, Hutubessy R, Kieny MP, Hill SR. Cost-effectiveness thresholds: pros and cons. Bull World Health Organ. 2016;94(12):925-30.

49. Aggarwal R, Ghoshal UC, Naik SR. Assessment of cost-effectiveness of universal hepatitis B immunization in a low-income country with intermediate endemicity using a Markov model. J Hepatol. 2003;38(2):215-22.

50. Griffiths UK, Hutton G. Das Dores Pascoal E. The cost-effectiveness of introducing hepatitis B vaccine into infant immunization services in Mozambique. Health Policy Plan. 2005;20(1):50-9.

51. Klingler C, Thoumi Al, Mrithinjayam VS. Cost-effectiveness analysis of an additional birth dose of hepatitis $B$ vaccine to prevent perinatal transmission in a medical setting in Mozambique. Vaccine. 2012;31(1):252-9.

52. Guidozzi F, Schoub BD, Johnson S, Song E. Should pregnant urban south African women be screened for hepatitis B? S Afr Med J. 1993;83(2):103-5.

53. Brook MG, Lever AM, Kelly D, Rutter D, Trompeter RS, Griffiths $P$, Thomas HC. Antenatal screening for hepatitis B is medically and economically effective in the prevention of vertical transmission: three years experience in a London hospital. Q J Med. 1989;71(264):313-7.

54. Jonsson B. Cost-benefit analysis of hepatitis B vaccination. Postgrad Med J. 1987;63(Suppl 2):27-32.

55. Koretz RL. Universal prenatal hepatitis B testing: is it cost-effective? Obstet Gynecol. 1989;74(5):808-14.

56. Hahne SJ, Veldhuijzen IK, Wiessing L, Lim TA, Salminen M, Laar M. Infection with hepatitis B and C virus in Europe: a systematic review of prevalence and cost-effectiveness of screening. BMC Infect Dis. 2013;13:181.

57. Eckman MH, Kaiser TE, Sherman KE. The cost-effectiveness of screening for chronic hepatitis B infection in the United States. Clin Infect Dis. 2011;52(11): 1294-306.

58. Guinto RL, Curran UZ, Suphanchaimat R, Pocock NS. Universal health coverage in 'One ASEAN': are migrants included? Glob Health Action. 2015; 8:25749.

59. Chen DS. Hepatitis B vaccination: The key towards elimination and eradication of hepatitis B. J Hepatol. 2009;50(4):805-16.

60. Bulbul A, Karadag A, Koklu E, Pamuk U, Sarici SU. Anaphylactic shock due to hepatitis B immunoglobulin in a newborn. J Matern Fetal Neonatal Med. 2010;23(10):1257-9.

61. Khuroo MS, Khuroo NS, Khuroo MS. Accuracy of rapid point-of-care diagnostic tests for hepatitis B surface antigen-a systematic review and meta-analysis. J Clin Exp Hepatol. 2014;4(3):226-40.

62. Lavanchy D. Hepatitis B virus epidemiology, disease burden, treatment, and current and emerging prevention and control measures. J Viral Hepat. 2004; 11(2):97-107.

63. Fourati S, Pawlotsky JM. Recent advances in understanding and diagnosing hepatitis B virus infection. [version 1; referees: 2 approved] F1000Research. 2016;5:1-8. doi:10.12688/f1000research.8983.1.

64. Kaji A, Parker DM, Chu CS, Thayatkawin W, Suelaor J, Charatrueangrongkun R, Salathibuppha K, Nosten FH, McGready R. Immunization coverage in migrant school children along the Thailand-Myanmar border. J Immigr Minor Health. 2016;18(5):1038-45.

65. Thio CL, Guo N, Xie C, Nelson KE, Ehrhardt S. Global elimination of motherto-child transmission of hepatitis B: revisiting the current strategy. Lancet Infect Dis. 2015;15(8):981-5.

66. Torreele $E$, Mazzucato M. Fair vaccine pricing please, not random acts of charity. BMJ. 2016;355:16173.

\section{Submit your next manuscript to BioMed Central and we will help you at every step:}

- We accept pre-submission inquiries

- Our selector tool helps you to find the most relevant journal

- We provide round the clock customer support

- Convenient online submission

- Thorough peer review

- Inclusion in PubMed and all major indexing services

- Maximum visibility for your research

Submit your manuscript at www.biomedcentral.com/submit
Biomed Central 